\title{
FAMILIA Y JÓVENES EN UN MUNDO QUE CAMBIA: ¿CÓMO EDUCAR Y ACOMPAÑAR LA RESPUESTA VOCACIONAL?
}

DOI: https://doi.org/10.52039/seminarios.v49i169.80

Autor: Amedeo Cencini. Profesor de Psicología Aplicada y de Pastoral Vocacional en la Universidad Salesiana de Roma.

(Tradujo del original italiano Paco Lansac)
La pastoral vocacional y la necesidad de una relación "ecuménica" con las pastorales hermanas: la juvenil y la familiar.

Por fin, un Encuentro vocacional "ecuménico", con un tema que muestra el contexto natural de la pastoral vocacional y, en cualquier caso, sin dejar de señalar las relaciones necesarias con las pastorales "hermanas", para situar en un contexto realmente eclesial el sentido de su presencia y de su misión.

Quien sigue con regularidad los Encuentros del Centro nacional de vocaciones notará la lenta pero segura evolución que ha ido dándose en esta dirección. Creo que es la dirección de la maduración eclesial, de la madurez de la fe y del testimonio y, en definitiva, de la madurez vocacional de una comunidad creyente. Sin lanzar cohetes al aire, pienso que podemos decir que se abre una nueva etapa en la argumentación y práctica vocacionales. Es significativo que sea Mons. Castellani el que abra esta etapa, ya que fue él mismo quien hace bastantes años puso las premisas y dio el impulso inicial que nos ha permitido llegar hasta aquí.

En lo referente a mi colaboración, no se me ha pedido explícitamente que entre a fondo en las interrelaciones entre las diversas pastorales, pero creo que no puedo pasar por alto al menos el indicarlas, e intentaré sobre todo 
señalar algunas premisas o condiciones de aquello que debería ser cada vez más el modo normal de hacer pastoral vocacional en la Iglesia.

El esquema que sigo es más bien el clásico. En la primera parte hago una descripción general de la situación de la familia y de la juventud de hoy. Después se intenta examinar brevemente nuestro modo de juzgar y vivir el cambio; unido al modo de percibir e interpretar la realidad, existe, sin duda, la posibilidad de acoger una llamada a la conversión y aquí, sin lugar a dudas, nace una posibilidad distinta de concebir también la pastoral vocacional, es decir, aquí nace propiamente la colaboración entre los diversos trabajos pastorales para converger en el mismo objetivo: el crecimiento de la Iglesia como comunidad de llamados y de personas que llaman.

\section{EL CAMBIO QUE NO CESA. ¿HACIA DÓNDE?}

El Documento de la CEI, del que parte nuestro Encuentro, habla con mucha precisión de un "mundo que cambia", dándonos a entender que no ha cambiado sino que está cambiando. Si hubiera cambiado, todo sería relativamente fácil porque podríamos tener ante nosotros un cuadro del momento casi definitivo como punto de referencia para los oportunos ajustes pastorales. En realidad no es así, el cambio sigue su curso; podemos solamente percibir algunas directrices, pero sin ninguna presunción de haber captado todo y sin aventurarnos a hacer pronósticos a largo plazo, por no decir que nos vemos obligados a estar cambiando todo continuamente; pero, eso sí, con el ánimo de avivar a fondo el análisis para ir captando el sentido de este cambio y hacer opciones coherentes. Es el coraje de la inteligencia de la fe.

Por otra parte, esta movilidad continua nos exige una gran capacidad de discernimiento, que es exactamente la virtud de quien sabe estar en el cambio y en la movilidad, del creyente que sabe escuchar el mundo y la historia y que ha aprendido a leer la presencia de Dios en los signos cambiantes y débiles, en los murmullos y en los fragmentos, en los segmentos ambiguos y retorcidos de la historia...., creyente humilde, porque sabe que no puede pretender la visión plena de la teofanía luminosa, solar y matutina, sino que debe contentarse con la cognitio vespertina, envuelta de penumbra oscura; creyente sin duda purificado porque ha aprendido a captar en lo que no aparece muy claro y en el detalle, en lo pequeño y en el límite, la presencia de lo Eterno, resistiéndose a la fácil tentación de reconocer lo divino sólo en los signos claros e inequívocos. Y esto ya nos da una orientación de fondo, ciertamente preciosa, que no aparece en absoluto en tiempos de búsqueda más visionarios que creyentes.

Vamos a tratar de centrarnos solamente en algunos elementos de este proceso en marcha, a nivel de familia y del mundo juvenil. 


\section{La familia en transición}

Nos interesa ver qué cambios de la institución familiar pueden tener una cierta correlación con nuestra argumentación y, por tanto, con el fenómeno vocacional.

\section{Cambios formales}

Ante todo, hay que decir que ha habido y sigue habiendo una transformación a nivel de la composición de los miembros de la familia y, por tanto, en lo que se refiere a la forma externa. Desde los años 70, al menos en Italia, hemos pasado de forma progresiva de la familia extensa (más núcleos cohabitando bajo el mismo techo) a la familia alargada (con más de dos generaciones en el mismo núcleo, por ejemplo, con la presencia de abuelos, con hijos casados y nietos), y de ésta a la familia nuclear normal (pareja de cónyuges con sus hijos). Tales modelos todavía persisten, pero van apareciendo y cada vez más otras formas: familia sólo con el padre o la madre (sólo padre o madre con los hijos), convivencia more uxorio (unión civil), familias reconstituidas (matrimonio de divorciados), familias multiétnicas (cónyuges pertenecientes a diferentes etnias), familias unipersonales (solteros, célibes, núbiles, viudos/as, divorciados...) ${ }^{1}$.

Desde esta perspectiva, cualquiera puede ver que estos cambios tienen que afectar a la función educadora que siempre ha tenido la familia, con la inevitable consecuencia indirecta en lo que se refiere a la disposición del hijo para hacer un proyecto de vida.

\section{Miedo al hijo e hijo huérfano, carencia educadora y confusión de funciones}

Tal vez sean más relevantes los cambios que se dan a nivel de relaciones, especialmente dentro de la dinámica familiar. Vamos a ver algunos.

Hemos pasado de la etapa del asesinato del padre (siguiendo el lenguaje psicoanalítico), de hace unos años, a la del miedo al hijo (véase la disminución de la natalidad), que contrasta con la pretensión opuesta de desearlo ${ }^{2}$ o desde luego desearlo a cualquier precio y de cualquier modo, pero progra-

1 Cf. P. Donati (ed.), Identità e varietà dell'essere famiglia. Il fenomeno della pluralizzazione, Milano 2002; cf. también el número de Famiglia Oggi XXV/11 (noviembre 2002).

2 Según una investigación del CNR (Consejo nacional de investigación) de hace tres años, Italia tiene un índice entre los más elevados de Europa en la apreciación del "valor de los hijos"; la última investigación de la Asociación demográfica italiana confirma que las parejas desean una media de 2,2 hijos (aun cuando es raro que en realidad nazca un segundo hijo); cf. G. Anzani, La clessidra della felicità : Avvenire 8/XII (2001). 
mándolo según los propios gustos y deseos; es decir, se da un modo de culto al hijo, con frecuencia hijo único y un reyezuelo sin oposición, con una especie de inversión de funciones, por la que los padres de hoy parecen ser la última generación de los hijos que, en su momento, han obedecido a sus padres, y la primera generación de padres, hoy, que obedecen a sus hijos ${ }^{3}$; padres siempre atentos y dispuestos a satisfacerles los deseos, recortando, consecuentemente, la capacidad de desear y proyectar. Inevitables y relevantes pues los efectos intrapsíquicos a nivel de capacidad y libertad de autocreatividad.

Siempre dentro de esta óptica y como consecuencia del mismo fenómeno de la inestabilidad de la familia y del descenso de la natalidad, se dan cada vez más hijos únicos, o hijos un tanto huérfanos, de una orfandad vertical (de uno de los padres, y no necesariamente porque alguno haya muerto), u horizontal-colateral (de un hermano que nunca ha existido). El fin de la "sociedad fraterna", dentro del núcleo familiar, significa un conjunto de carencias que pesan sobre el desarrollo posterior, especialmente en lo que se refiere a la capacidad de relaciones e interacción con alguien diferente, al descentramiento personal y a la seguridad interior

Otro hecho inquietante, en el que querría extenderme un poco más, es la carencia educadora de la familia. La familia va renunciando cada vez más a su función natural y primordial de ser educadora de aquellos a los que ella misma ha llamado a la vida. Y renuncia a ello cuando también ella misma respira y sufre la confusión ética que no distingue los ámbitos del bien y del mal, y carece del coraje de decir con claridad qué hay que hacer o qué hay que evitar, cuando algo no se puede aceptar. Renuncia a esa función cuando una idea de libertad mal entendida y un malentendido respeto hacia la libertad de los hijos le lleva a no ofrecer ningún punto de referencia, ninguna idea consistente de cara a la vida, ningún ejemplo hermoso y atrayente..., o cuando no se tiene el coraje de decir no a una cosa o de indicar que la renuncia es un camino insustituible de autorrealización. Permitir todo y satisfacer sistemáticamente cualquier petición es una verdadera ausencia educadora, es como estar ausente o contar muy poco en la vida de los hijos; es crueldad psicológica.

Pero se da otra confusión en el origen de la carencia educadora de la familia: la confusión de funciones. En la actualidad hay cada vez más niños que se comportan como adultos y adultos que se comportan como niños; pequeños a los que se les permite todo y que no se conforman con nada, tal vez más precoces y desinhibidos que los niños de antes, hasta el punto de parecer menos niños y más adultos; y hay jóvenes que no encuentran camino para irse de casa, de asumir responsabilidades, de comprometerse con alguien

${ }^{3}$ Así lo expresa el actor Pino Caruso: "Cuando era hijo, obedecía a los padres. Ahora que soy padre, obedezco a los hijos. La mía es una generación que nunca ha tenido autoridad". 
para siempre, de optar por algo de modo definitivo... y que permanecen eternos "hijos de familia", sin duda con personalidad frágil y dejándolo todo en

el aire. Lo extraño es que frecuentemente no se da un cambio en la persona por esta singular inversión; los niños precoces de un momento son los que después no se deciden nunca a hacerse adultos ${ }^{4}$.

Asimismo, nos encontramos con padres que parecen "huir" de sus funciones y evitan el dar razones de lo que exigen y conceden a los hijos, prefiriendo simplemente imponerse; también hay padres que de una forma, digamos que un tanto patética, buscan enmascarar la función natural de autoridad con una estrategia de campechanería y complicidad, comportándose como amigos de sus hijos, tal vez imitándoles y mostrándose como "jóvenes" o juveniles al precio que sea. Y todavía más, hay padres que juegan a hacer de madres, buscando y copiando formas de relación maternas o femeninas, con el riesgo de perder autoridad y credibilidad; o madres que todavía parecen buscar mitos (y ritos) femeninos extraños, casi avergonzándose de ser madres y acabando por convertirse, exagerando un poco, en una especie de "prótesis metálicas". El resultado de este supuesto juego de las cuatro esquinas será una desorientación general en la educación de los hijos: el hijo de un padre "fugitivo" es siempre un hijo poco adulto, sin autoestima ni espina dorsal; a un padre que no ha sabido asumir a su tiempo la autoridad le corresponderá un hijo que no tiene puntos de referencia ni sabe darle a su vida una orientación; finalmente, un padre que ha jugado a hacer de madre tendrá un hijo con problemas de identidad, esto por lo menos, y problemas de relación con el otro; una madre con poco calor materno y demasiado preocupada de su feminidad difícilmente contagiará una seguridad emotiva, que es la base que capacita para poder hacer una elección. En resumidas cuentas, la carencia educadora por parte de la familia crea a su vez personas incapaces de descubrir las funciones propias de padres, padre y madre, y a su vez repetirán los mismos errores y tendrán la misma carencia en el campo de la educación. Y el juego de disfraces seguirá...

\section{La familia, ¿sigue siendo un evento vocacional?}

En este mundo en cambio, la primera impresión que se tiene es que la familia parece cada vez menos un lugar de vocaciones. Por su parte, la Iglesia sigue considerando a los padres como "los primeros educadores vocacionales"5.

${ }^{4}$ Cf. G. Savagnone, L'infanzia amarrita: Evangelizzare 2 (2002).

${ }^{5}$ Nuevas vocaciones para una nueva Europa, Madrid 1998, 8; cf. Familiaris consortio, 39 . 
No es el lugar de vocaciones sacerdotales y religiosas, o mejor dicho, no es el lugar que fue en otro tiempo. Pero el problema tal vez sea otro, más general y radical: la familia ya no es lugar vocacional en cuanto tal, es más un nido y menos una pista de lanzamiento hacia nuevos itinerarios y proyectos de vida, no provoca a salir, a buscar y a encontrar el puesto de uno en el mundo, no da aquella seguridad básica y emotiva de la que proviene la fuerza de amar al otro para siempre, a él o a ella, entregándose para dar vida al lado de una realidad distinta de uno mismo 6 . Vuelvo a hacer hincapié en esto: el fenómeno de la "familia, dilatada en el tiempo, del joven adulto"7, o de los veinticinco o treinta años viviendo alegremente en casa de los padres, es signo de que aquélla está yendo a menos en su propia vocación de generar vocaciones, dejando de ser no sólo lugar de vocaciones, con los padres que estimulan animosamente (cuando todo va bien) hacia ideales nobles de vida, sino dejando de ser ella misma evento vocacional, en cuanto objeto de una llamada y sujeto que llama y pro-voca. Ciertamente, el fenómeno es complejo y ligado a factores de orden social general, sobre todo de tipo económico (el homo oeconomicus desteta tarde, tiene necesidad de muchas garantías si apuesta en la Bolsa, pero a menudo es un desadaptado en la vida y un desmañado en los afectos...), pero asimismo expresa una incapacidad por parte de los padres al practicar una "pedagogía del abandono" y del distanciamiento, físico y afectivo.

En todo caso, el problema no es sólo y primariamente "religioso", sino psicológico-antropológico, con una consecuencia indirecta, digámoslo una vez más, en la capacidad de afrontar decisiones por parte del joven.

\section{Los jóvenes en... transición continua}

Pocos temas son tratados con una abundancia de datos y con una variedad de análisis como el del "mundo juvenil", hasta el punto de alcanzar en ciertos casos conclusiones casi contradictorias

\section{Datos que se contradicen}

Hace tiempo me tomé la molestia de recoger algunos de estos datos, por regla general caracterizados, no sé por qué, por un juego casi voluptuoso de masacrar la categoría del mundo juvenil ${ }^{8}$. Podríamos comenzar por algunas

${ }^{6}$ Cf. A. Cencini, Lezioni di gratitudine tra le mura domestiche: Vita Pastorale 5 (2002) 122-123.

7 Cf. G. Campanini, Famiglia, en Varios, Dizionario di pastorale vocazionale, Roma 2002, 490 (edición castellana en preparación, Ediciones Sígueme, Salamanca).

${ }^{8} \mathrm{He}$ mostrado estos y otros datos, analizándolos desde un punto de vista vocacional, en mi libro Alguien te llama: carta a un joven que no sabe que es llamado, Santander 2002. 
frases aparentemente lapidarias, una especie de fotografía que no expresa ciertamente la actitud habitual. Son sólo algunos ejemplos de afirmaciones que se excluyen mutuamente y que expresan bastante bien lo difícil que resulta ajustar el objetivo para hacer esta foto:

- "los jóvenes de hoy están solos...", "los jóvenes de la sociedad masificada no saben estar solos.."

- "la juventud de nuestro tiempo teme la relación...", "la nueva generación ha descubierto la relación..."

- "la generación de los jóvenes de hoy es una generación sin padres ni maestros...", "nunca ha existido tanta demanda de guía y dirección espiritual como en los jóvenes de hoy"

- "ya no hay padres..." "después del crimen ocurrido en la ciudad Novi Ligure, despunta la figura del padre..."

En resumidas cuentas, realmente, ¿de qué parte está la verdad sobre los jóvenes? Se tiene la misma sensación cuando observamos las caracterizaciones hechas por el investigador de turno habitual, que a menudo profiere juicios que acaban desmintiéndose entre ellos.

He aquí una prueba. Según estos "expertos", aquella generación juvenil sería "una generación sin padres ni maestros", "una generación de lo cotidiano"10, "una generación de lo privado"11; y vosotros seríais "jóvenes sin recuerdos"12, "muchachos sin tiempo"13, "mundo de los que viven el vacío" o jóvenes "del vacío"14, jóvenes semejantes a "sonidos del silencio"15, "muchachos sin tutela"16, "corazones violentos"17, "edad incompleta"18,

${ }^{9}$ Cf. L. Ricolfi-L. Sciolla, Senza padri né maestri. Inquiesta sugli orientamenti politici e culturali degli studenti, Bari 1980.

$10 \mathrm{Cf}$. F. Garelli, La generazione della vita quotidiana. I giovani in una società differenziata, Bologna 1984.

11 Cf. S. Scanagatta, Giovani e progetto sommerso. Inchiesta sulle tendenze culturali dei giovani negli anni '80, Bologna 1984.

12 Cf. L. Ricolfi-L. Sciolla, Vent'anni dopo. Saggio su una generazione senza ricordi, Bologna 1989.

13 Cf. M. Canevacci y otros, Ragazzi senza tempo. Immagine, musica, conflitti delle culture giovanili, Genova 1993.

${ }^{14}$ Cf. P. Crepet, Le dimensioni del vuoto. I giovani e il suicidio, Milano 1993. no 1994.

15 Cf. C. Baraldi, Suoni del silenzio. Adolescenze difficili e intervento sociale, Mila-

16 Cf. S. Bisi-G. Brunello, Ragazzi senza tutela. Le opinioni di undicimila giovani, Venecia 1995.

17 Cf. P. Crepet, Cuori violenti. Viaggio nella criminalità giovanile, Milano 1995.

18 Cf. COSPES, L'età incompiuta. Ricerca sulla formazione dell 'identità negli adolescenti italiani, Leumann-Torino 1995. 
"jóvenes despilfarradores"19, "generación en éxtasis"20; sin rodeos, "generación invisible" 21 . Pero he encontrado también otros calificaciones de esta realidad juvenil: "los inesenciales", "los sacrificados", "los que no participan", "los confundidos", "los resignados", "los extraviados en los laberintos afectivos y sexuales", o "aquellos que no saben lo que quieren y lo que no quieren"22, o la "generación de la gran indecisión"23. "Hay también formas graciosas con las que algunos educadores clasifican el mundo juvenil, atribuyéndole sobrenombres curiosos y expresivos según los distintos modos de ser o de comportarse: existiría el tipo "inoportuno" o bien el "bonsái", o el "cirineo" y hasta el "aquilón", pero existen también el "píldora", el "extravagante", "el prisas", el "tóxico", por no decir el "ecologista", el que pertenece al "baby-gang", mientras perduran inoxidables los "hijos de papá"24.

\section{¿Y el "llamado"?}

Me gustaría decir que falta una calificación: el "llamado". Y esto puede deberse en parte a que es poco visible e insignificante en las estadísticas, y en parte porque los instrumentos de observación no están preparados para captar el misterio de la vocación y menos aún la exigencia interior presente en todo joven de pensar su futuro y de pensarlo no sólo para tener "un puesto o una ocupación", de proyectar sus días en una perspectiva que vaya más allá del momento, de responder a una voz que no se capta inmediatamente y que puede tener algo importante que decirle, de encontrar una presencia fiel y dejarse acompañar por ella.

Y éste es quizá el problema: las nuevas generaciones crecen en un contexto de creciente y avanzada secularización ${ }^{25}$, que en sus nuevas manifestaciones no consiente la lectura del fenómeno vocacional, puesto que no cuenta en su vocabulario ni siquiera con el término vocación, o lo entiende de manera cercenada, o lo refiere inmediatamente a una realidad que está totalmente fuera de sus intereses.

En tal contexto, el cristianismo está tratando de buscar y encontrar un nuevo equipamiento, no sin sufrimiento y purificaciones. $Y$ tal vez este Encuentro asume sin darse cuenta esta lógica. Si por una parte es imposible

19 Cf. S. Pistolini, Gli sprecati, Milano 1996.

${ }^{20}$ Cf. F. Bagozzi, Generazione in ecstasy. Droghe, miti e musica della generazione techno, Torino 1996.

${ }^{21}$ Cf. F. Farinelli, La generazione invisibile: Rocca 19 (1998) 20-22.

22 Cf. I giovani: lo sbando e la nostalgia: Il Gabbiano 4 (1998) 12.

23 L. Cherubini, Il Grande Boh, Milano 1998.

24 Cf. A. Mazzi, Un'ala di riserva, Milano 2000.

25 Cf. C. Buzzi-A. Galli-A. De Lillo (eds.), Giovani del nuovo millennio. Quinto rapporto IARD sulla condizione giovanile in Italia, Bologna 2002. 
restaurar el pasado, por la otra es justo pensar en una pastoral que busque un nuevo enganche con el mundo juvenil a partir de los problemas reales de su mundo y no de los de la institución. Y esto ya es una conversión, o la "conversión" que está en la base de una auténtica pastoral vocacional hoy, como veremos mejor más adelante. Y sin temer por ello a que podamos traicionar los intereses de la Iglesia. Al contrario.

\section{La "adultescencia"}

¿Cuál es de hecho el problema real de tantos jóvenes hoy? ¿No es el de su incapacidad de decisión, de diferir indefinidamente las decisiones, de aplazar cualquier tipo de opción o de no decidirse nunca? ¿No es ésta la causa de permanecer en la familia, como ya vimos, prorrogando la permanencia hasta bastante más tarde de lo que ha sido habitual?

Todo esto daría pie para lo que algún psicólogo hoy comienza a llamar, con una palabra nueva y extraña, la adultescencia, cuyo origen es la unión de dos términos, adulto y adolescencia. Con ella se quiere significar un adolescente que entra en el estado adulto, pero como adolescente, o sin renunciar del todo a ser adolescente, o sin saber abandonarlo completamente, hasta el punto de comprender su estado adulto como una prolongación de su adolescencia.

Tendremos así una simulación de adulto, destinado a permanecer para siempre como el joven de las bellas promesas que nunca se realizan, o el posadolescente que no se decide nunca a hacer una opción radical, o que teme tomar decisiones que le aten para siempre, sean del tipo que sean, o que parece jugar con la vida, consigo mismo o con los otros, dejándose siempre una puerta abierta en las propias decisiones para que así no aparezcan como definitivas. De este modo, si me caso contigo podremos separarnos apenas aparezca alguien que me agrade más que tú; si quedas en estado, podrás abortar si no te gusta el tener un hijo ahora o no te agrada tenerlo conmigo, o también si el bebé querido y "molesto" nos va a desbarajustar los planes; si escojo este camino, trabajo o vocación siempre podré cambiar si la cosa no me va bien ${ }^{26}$. La adultescencia juega con la vida, es como un hacer zapping delante la televisión con el mando entre las manos, creyéndose ser libre porque salta como un canguro de aquí para allá sin realmente comprometerse con nada; en realidad, el adultescente tiene miedo de dejar las cosas, de tener que renunciar..., o teme hacer opciones equivocadas de las que tenga que arrepentirse después..., o no tiene criterios o puntos de referencia para orientar sus opciones, o ha encontrado el modo de "escaquearse" del tener que escoger..., y al no haber aprendido a decidir no ha aprendido a vivir.

26 Cf. A. Cencini, Scegliere: Mondo Voc 6-7 (2002) 18-19. 
Ahora bien, desde nuestro punto de vista, esto es muy interesante, puesto que de alguna manera ensancha el campo de acción o extiende el ámbito de referencia de nuestro diálogo sobre la vocación. Es algo que sobrepasa el contexto puramente eclesial, incluso va más allá del ámbito de los creyentes. Si verdaderamente es cierto que, como dice H. Arendt, el hombre es esencialmente un ser que decide, o que la decisión es lo que caracteriza esencialmente al ser humano, hoy nos encontramos delante de lo que podríamos llamar una regresión de la especie. El problema vocacional es problema antropológico, no es un problema único de seminarios vacíos o parroquias desguarnecidas, es un asunto que atañe a la sociedad civil y, por tanto, a todos, y que hay que afrontarlo necesariamente con una mentalidad abierta, que va a la raíz del problema y del cambio acontecido en estos últimos tiempos, más allá de perspectivas miopes y mercantiles, con la unión inteligente de fuerzas y corazones.

Permítanme una última anotación a este párrafo sobre las transformaciones de la actual generación juvenil: si adultescente es el joven adulto que no se decide nunca, sería una dificultad añadida si así fuera también el joven animador vocacional. Hay quien dice que en nuestros seminarios hay también clérigos adolescentes. No puede ciertamente ayudar a decidirse quien todavía afronta la vida con mirada adolescente.

\section{EL VERDADERO PROBLEMA: QUÉ LECTURA PODEMOS HACER DEL CAMBIO}

Para llegar a delinear la pedagogía de la animación vocacional dentro de esta lógica del cambio, como es nuestro objetivo, no basta fotografiar correctamente la situación y sus puntos débiles, proyectar una acción capaz de responder a todo ello, sino que es necesario, al menos así lo creo yo, interrogarnos sobre la calidad de nuestra lectura del cambio, sobre nuestro modo de escuchar, sin dar por supuesto que sabemos leer bien la situación, que escuchamos sin prejuicios la historia, que somos capaces de situar dónde están realmente los problemas. Nosotros solemos estar convencidos de que no tenemos problemas perceptivo-interpretativos, creemos que sabemos leer (y...escribir), nos creemos buenos conocedores de la realidad, no se nos pasa por la cabeza estar condicionados por fenómenos que entorpecen la lectura de lo real, como las distorsiones perceptivas, o fenómenos de sordomudismo, de visiones preconcebidas, de analfabetismo pastoral.... Y peor aún si uno nunca ha oído hablar de esto, porque entonces no estará en condiciones de controlar las consecuencias. Hará opciones pastorales y pedagógicas equivocadas, también en el ámbito vocacional. 


\section{Centralidad de la escucha}

El documento que está en la base de nuestra reflexión (Comunicare il vangelo in un mondo che cambia) pone como icono bíblico el conocido prólogo de la primera carta de Juan: "Lo que existía desde el principio, lo que hemos oído, lo que hemos visto con nuestros ojos, lo que hemos contemplado y han tocado nuestras manos acerca de la palabra de la vida, -pues la vida se manifestó y nosotros la hemos visto y damos testimonio, y os anunciamos la vida eterna que estaba junto al Padre y se nos manifestó-, lo que hemos visto y oído os lo anunciamos para que también vosotros estéis en comunión con nosotros. Nosotros estamos en comunión con el Padre y con su Hijo, Jesucristo. Os escribimos estas cosas para que vuestro gozo sea completo" (1 Jn 1-4).

En este texto, el verbo que abre y cierra el párrafo es siempre el mismo: oír, o mejor dicho, oír/ver, porque el escuchar es siempre cuestión de ojos y oídos. En medio del párrafo, están todos los otros verbos, todos dentro del horizonte de esta escucha originaria que podríamos traducir por "acogida" radical de la propia identidad, como el dejarse continuamente hacer por parte de Dios en Cristo por el Espíritu y, precisamente por esto, ser signo y posibilidad para los otros, o precisamente por este dejarse hacer, asumir también las líneas estratégicas de la propia intervención educadora. El texto expresa maravillosamente el dinamismo profundo de la tarea pastoral-pedagógica de la Iglesia como lugar en el que ella "escucha y habla a partir de lo escuchado", es decir, recibe su identidad al escuchar el evento que la genera y que trasmite a los otros, pero que también "vuelve" a ella enriquecido por el juego de la dinámica relacional; dicho de otra forma, el creyente no sólo acoge su identidad como algo estático y fijo en el misterio que celebra, sino que la descubre y acoge como algo vivo y dinámico de la experiencia más global del anuncio de este evento, puesto que ello sucede (acaece) cada vez que un creyente expresa lo que ha visto, oído, y lo comparte con otros para conducirles también a la misma experiencia y a la alegría de la que habla Juan. Y de este modo, escuchar y leer, interpretar y vivir la situación es importante y decisivo para la propia identidad. Ésta es la razón por la que creo importante introducir este parágrafo en nuestra reflexión.

Pero, ¿qué tipos de escucha son posibles?

\section{Tres figuras de pedagogía pastoral, tres escuchas y tres pedagogías vocacionales}

No hace falta ser muy expertos para darnos cuenta de que hay diversos modos con los que la Iglesia piensa y lleva a cabo su compromiso pastoral y 
pedagógico en este campo. Podemos reconocer fácilmente tres figuras pastorales, y en ellas identificar otras tantas figuras pedagógicas vocacionales ${ }^{27}$.

\section{La boca sin orejas (una nueva propuesta)}

Existe una pastoral que parte de la precomprensión de una Iglesia depositaria de la salvación de una vez por todas, y de una salvación que ya está definida en sus contenidos, en sus formas celebrativas, en sus exigencias éticas, en las modalidades organizativas y de relaciones que derivan de ella. Se trata de una pastoral autorreferencial, inmóvil, que conforma no sólo a las personas y las culturas en un único estereotipo, sino que también lo hace con el mismo mensaje, dicho y dado de una vez por todas. Como consecuencia, se da una pastoral sorda, además de autorreferencial. Tiene boca, pero no orejas. No es que no se dé la escucha, hay espacio para el análisis de la situación, pero se hace a partir de la propia visión del mundo y a la vista de la confirmación posterior de la necesidad que tiene el mundo de esta palabra. Es pues una escucha centrada del todo en uno mismo.

Tal visión de la Iglesia y de la pastoral defiende que la conversión eclesial en lo que se refiere a su actuación está en la necesidad de una mayor claridad y valentía en la exposición de la verdad, aquella verdad de la que se ha hablado antes. Y tal visión determina una pedagogía vocacional, pedagogía que va sobre todo en la línea de un volver a proponer los estados vocacionales clásicos, pero con particular o exclusiva atención a las necesidades de la Iglesia institucional (la escucha esta centrada en ella misma) y poca disposición para acoger necesidades nuevas, perspectivas nuevas, problemas nuevos, dones nuevos, recursos nuevos, vocaciones nuevas 28 ..., en un mundo que cambia y que, por tanto, supone y exige novedad. Por este mismo motivo no sentirá mucho la necesidad de abrirse a una colaboración inteligente y complementaria con otros agentes educadores, civiles (culturales y sociales) y tal vez incluso eclesiales (con otros ámbitos pastorales): se ve el problema como si sólo fuera un problema eclesial y dentro de la Iglesia, y sólo problema vocacional sacerdotal o, a lo sumo, religioso (en cuanto estado subsidiario para las necesidades de la Iglesia). Son todas ellas consecuencias estrechamente unidas entre si y engarzadas al hecho de no escuchar al mundo que cambia, ni tener percepción alguna del cambio.

27 Tomo como punto de partida, para este análisis, una mesa redonda sobre la "escucha", que tuvo lugar recientemente en el Studio Teologico S. Zeno di Verona, y algunas intuiciones interesantes de $\mathrm{E}$. Biemmi.

28 Cf. Nuevas vocaciones para una nueva Europa. 
A lo más, se da el presupuesto de que una claridad mayor y valentía en la exposición de la verdad teológica de la identidad sacerdotal será suficiente para un despertar vocacional. Para entendernos, es una postura un poco neoiluminista, que da por supuesto que un mejor conocimiento facilitará también la elección, afirmando que hoy lo que se da es la pusilanimidad y la falta de seguridad en los agentes pastorales, casi un complejo de inferioridad, en lo que se refiere al anuncio de la vocación sacerdotal (que puede ser verdad, tal vez). Más aún, tal orientación pedagógico-pastoral tiene sus sospechas en lo referente a la ampliación del concepto de llamada a todos los estados de vida, incluido el laical; ve el peligro de que quede aguada la idea auténtica de vocación y de la misma pastoral vocacional, debilitada por genérica y confusa, según esta visión del tema.

Interesante aquello que podríamos considerar el indicador vocacional de este tipo de pedagogía vocacional y que, aunque no dicho explícitamente, está constituido sobre todo por el criterio numérico-cuantitativo de nuevos adeptos al culto, sin atención a otras opciones vocacionales. Se corre así el riesgo de prestar menos atención a la calidad del que ha sido llamado a la vida sacerdotal, a su trayectoria y testimonio vocacional.. Es un poco aquello que ocurría en el pasado (y en parte y en ciertos ambientes parece repetirse hoy), cuando las vocaciones presbiterales eran tan abundantes y tan satisfactorio el número que no hacía falta interrogarse sobre la calidad del comportamiento vocacional de la Iglesia en general y de las respuestas personales en particular (si es cierto, y no cabe duda alguna, que hoy no todos aquellos que podrían consagrarse se consagran, ayer, no todos aquellos que se consagraron debían haberlo hecho...). Para entendernos, sabemos cuánta gente moría en Italia durante e inmediatamente después de la guerra, en el siglo pasado, y por causa de la pelagra: enfermedad por la que se moría, aun habiendo comido e incluso sintiéndose uno saciado, porque la polenta, elemento básico de toda comida de cualquier familia en aquel momento, no tenía y no tiene suficiente carga nutricional; la gente comía, llenaba el vientre y no sentía el hambre, pero en realidad no se nutría adecuadamente y a la larga moría: es decir, el indicador daba señales positivas, pero era un indicador equivocado. No basta pues hacer estadísticas gloriosas o centrarse en la cantidad (es cierto que "el hombre en la prosperidad no comprende..."). La vida de la Iglesia, que se rige por la calidad de la respuesta del individuo, de todo creyente, a la constante llamada de Dios Padre, es sin duda otra cosa distinta.

El planteamiento de este estilo pastoral con la correspondiente pedagogía vocacional, como hemos señalado, parece algo del pasado, pero hoy hay quien tiene nostalgia de ello y está convencido de que podría resolver los problemas de la crisis vocacional (y seguramente "reclutaría" vocaciones). 


\section{Una sola oreja y muchas bocas (reproducción/clonación)}

Se da una segunda comprensión de la pastoral y de su correspondiente pedagogía, que deriva de otra autocomprensión de la Iglesia, una pastoral generosa y animada por el deseo de una comunicación sincera del evangelio, con una intención fuertemente misionera. Esta Iglesia caracterizada por el anuncio, está convencida de poseer una perla preciosa, pero se da cuenta de la dificultad que supone el comunicarla. Y por ello afirma que el problema principal reside en el hecho de que pueda ser captada, y que la escucha por parte de unos y otras, la única escucha que les volvería libres y capaces de una respuesta vocacional, está obstaculizada por una serie de filtros y distorsiones auditivas de tipo cultural y mediático. Aquí pues existe la escucha, y una escucha atenta, a menudo contando con la ayuda de investigaciones sociológicas y con debates sobre la situación; pero es una escucha unidireccional, estratégica, de cara a una mejor transmisión del mensaje, creyendo que todo está ya dispuesto, confeccionado y listo para usarse, independiente, digamos, de quien lo anuncia y de quien lo recibe. Por esto es unidireccional, aunque generosa y motivada; está marcada todavía por una idea de vocación, que es sobre todo la sacerdotal y la religiosa, y también por una visión de Iglesia, donde las otras vocaciones, aunque teóricamente reconocidas, se sitúan en un nivel inferior y se les presta menos atención.

De todo ello resulta una pedagogía vocacional a menudo activa, creativa, pero caracterizada por una escucha de todo menos de que los agentes vocacionales puedan replantearse la situación. El mensaje vocacional aparece siempre como aquel que, una vez formulado adecuadamente por el animador vocacional, dependerá sólo del destinatario del mensaje el recibirlo o no y el responder o no. Pero el animador no se siente más implicado, no va más allá, su única dificultad será la de encontrar las modalidades comunicativas más eficaces y los argumentos más convincentes. Escucha al otro, pero si responde que no, o dice que no está interesado en ello, le deja inmediatamente, no se cuestiona el cómo ha hecho la propuesta ni el significado de aquella negativa (que tal vez no es sólo negativa), no se cuestiona el contenido de su propuesta ni si ella contiene la mejor orientación para todos o sólo para los mejores, la posibilidad de que su anuncio verdaderamente abra y no cierre caminos, ni se plantea la veracidad de su idea de vocación...., no está dispuesto a plantearse todo esto, o, a lo sumo, está dispuesto a volverlo a ver pero sólo pensando en el objetivo que tiene en mente, sin estar mínimamente afectado por la respuesta negativa del otro. No se le pasa por la cabeza que aquel "no" a la propuesta vocacional sacerdotal explícita no puede en cualquier caso negar la exigencia vocacional inscrita en lo más profundo de todo ser humano, en todo joven, y que sobre esta base puede tal vez reencontrarse con el mismo joven en cuanto que es, sin duda alguna, un ser vocacional, disponible seguramente en alguna de las perspectivas vocacionales. 
Visto todo esto, debe cuestionarse si su idea de vocación en un sentido único es la correcta; si su idea de Iglesia como asamblea de...pocos llamados y todavía menos de personas que llaman sea evangélica; si aquel "no" no oculta los "sî" que habría que sacar a flote y sobre los cuales podría y debería afrontar la relación con los jóvenes; si es correcto o evangélico abandonar a un joven porque dice no estar interesado en la idea de hacerse sacerdote. Esto implica una gran conversión y que con frecuencia está ausente en los programas de animación vocacional.

Existe por ello un pragmatismo voluntarista, por un lado, y una falta de flexibilidad substancial en los contenidos de la propuesta. Y de este modo, un animador tan exacto estará en otro sitio para repetir a los otros la misma invitación, con el mismo proceder inflexible en la forma de actuar: o lo tomas o lo dejas. En resumidas cuentas, una sola oreja y muchas bocas. En el fondo, busca una reproducción de sí mismo, hasta llegar casi a la clonación.

Por tanto, éste no se contenta, como en el primer caso, con reforzar claramente la identidad teológica, será más vivo y emprendedor, también más moderno y convincente, pero substancialmente será todavía esclavo de una lógica vocacional más bien restringida y limitada. Una lógica que supone un mundo que no ha cambiado para nada o, a lo sumo, que ha cambiado pero no hasta el punto de que yo también cambie. Y normalmente sucede, como consecuencia inevitable, que cuando la idea de vocación se aplica sólo a un cierto tipo de llamadas, no entra en acción ninguna exigencia de colaboración con los otros servicios de pastoral; al contrario, aparecerá un clima de competencia y concurrencia, o de uso instrumental de la colaboración, aceptada sólo si el otro trabaja para mis objetivos o según mis esquemas.

El indicador pastoral de esta pedagogía estará representado, en este caso como en el precedente, por el número de aquellos que entran en el seminario o por criterio mercantil. Y si el modelo precedente parece algo propio de tiempos pasados, éste parece con frecuencia el modo actual de proceder en el campo vocacional.

\section{Dos orejas y una boca (generación y autorregeneración)}

Existe una tercera comprensión de la pastoral vocacional, que responde a una autocomprensión distinta de la Iglesia, aquella que en teoría subyace en el texto de 1 Jn 1, 1-4 y en el Documento de la CEI (Conferencia episcopal italiana) sobre la comunicación de la fe en un mundo que cambia, especialmente cuando recomienda "hacer un esfuerzo por escuchar la cultura de nuestro mundo, discernir las semillas del Verbo ya presentes en ella, también más allá de los confines visibles de la Iglesia. Escuchar las expectativas más íntimas de nuestros contemporáneos, tomarse en serio sus deseos y búsquedas, tratar de ver qué es lo que hace arder sus corazones y que es, por el contrario, lo que les 
suscita miedo y recelo, es importante para podernos hacer servidores de su alegría y de su esperanza. Además, no podemos de ninguna manera excluir el que los no creyentes tengan algo que enseñarnos en relación a la comprensión de la vida y que, por tanto, por caminos inesperados, el Señor puede en ciertos momentos hacernos sentir su voz a través de ellos"29. Una pastoral que se toma en serio este texto es una pastoral que está convencida de que el evangelio está todo dicho y todo por explicitar, y que en este trabajo inagotable de hermenéutica son necesarias dos orejas, dos fidelidades juntas: al evento que nos ha generado y a la cultura en la que nos movemos, al evangelio y a los hombres y mujeres de hoy. Una Iglesia así sabe que no puede estar fuera de este proceso vivo y en cambio, como sabe dar en la medida en que recibe.

La pedagogía vocacional que expresa este modelo de Iglesia no es funcional para simplemente transmitir mejor el evangelio, ni tampoco para producir únicamente vocaciones de un cierto tipo, sino para que ella misma comprenda cada vez mejor el evangelio y la propia identidad eclesial desde ese mismo evangelio, para dejarse enriquecer y definir en la identidad propia de esta doble escucha. Si, en efecto, la Iglesia es evento vocacional (comunidad de llamados y de personas que llaman) y si ella misma, en la medida en que la llamada que viene de lo alto (de aquel Dios que llama porque ama, y por tanto que ama siempre) es reconocible y audible y abre nuevos horizontes y traza nuevos caminos, entonces genera nuevas respuestas y nuevas vocaciones. Por eso, la escucha, de la que hemos estado hablando, genera y regenera la Iglesia, y la convierte en generadora de vida y de vocaciones, porque por esta escucha capta la realidad y la riqueza, antes que la necesidad y la urgencia de nuevas vocaciones. Así la Iglesia se descubre a sí misma y descubre su propia identidad de comunidad continuamente llamada y que llama, pero que no es hacedora y propietaria ni destinataria final de las vocaciones.

Por eso podemos decir sin rodeos que esta pastoral pone los cimientos de una auténtica pedagogía vocacional, la del diálogo vocacional, en la que este diálogo no es sólo estrategia misionera (o mercantil, como en el caso precedente), sino el rasgo distintivo de su identidad, ya dada pero también por hacer, y esto porque la vocación en la Iglesia no es sólo función o respuesta a una necesidad institucional, sino que antes que nada es expresión de la imagen del Creador impresa en la criatura, imagen evidentemente inagotable y, por tanto, fuente de la extraordinaria variedad de las vocaciones en la Iglesia. Y si, por un lado, el diálogo vocacional conduce al verdadero fin de toda pastoral (conducir al creyente al encuentro dialogal con Dios), por el otro, es sólo en el diálogo, y en el diálogo vocacional y a través de él, como pueden surgir

29 CEI, Comunicare il vangelo in un mondo che cambia, 34. 
las diversas vocaciones en la Iglesia, como rasgos distintivos del rostro del Hijo; es sólo a través del diálogo como el animador vocacional puede contemplar con sorpresa la novedad de las llamadas y favorecer la originalidad de las respuestas, haciendo que emerjan todas ellas en su novedad inédita, fruto de la fantasía del Espíritu, sin imponerles una única salida, ni violentarles la originalidad. Si todo ser humano tiene su vocación desde el momento de su nacimiento, necesariamente se dan varias vocaciones en la Iglesia y en el mundo. "La Iglesia particular es como un jardín florido, con gran variedad de dones y carismas, movimientos y ministerios" 30 .

Precisamente por esto, el Documento del Congreso europeo vocacional tiene un parágrafo que se corresponde con el del número 34 del Documento de la CEI, ya citado, y pide a la Iglesia que esté a la escucha de las "expectativas de los hombres, que lea aquellos signos de los tiempos que constituyen código y lenguaje del Espíritu, que entre en diálogo crítico y fecundo con el mundo contemporáneo" 31 , para después especificar que "toda vocación es 'necesaria' y 'relativa' al mismo tiempo. 'Necesaria', porque (a través de ella) Cristo vive y se hace visible en su cuerpo que es la Iglesia y en el discípulo que es parte esencial en ella. 'Relativa', porque ninguna vocación agota el signo testimonial del misterio de Cristo, sino que expresa sólo un aspecto. Sólo el conjunto de los dones hace epifánico todo el cuerpo del Señor. En el edificio, toda piedra tiene necesidad de la otra (1Pe 2,5); en el cuerpo, todo miembro tiene necesidad del otro para hacer crecer el conjunto del organismo y contribuir al bien común" (1Cor 12,7)"32.

Será, por tanto, una pedagogía de mucha escucha y respeto para que se realice la vocación de la Iglesia, vocación de ser "madre de vocaciones porque las hace nacer en su interior..., las protege, las alimenta y las sostiene"33, pero también podemos hablar de "hija" de esta floración vocacional, o su expresión y fruto, regenerada continuamente por ella. Una Iglesia, en la que sólo algunos merezcan o sean considerados dignos de ser llamados para ser o hacer algo, no funciona, está como anquilosada y desconcertada, da una imagen decadente, aunque estos llamados fuesen muchos y santos; sólo una Iglesia en la que todos son llamados (y que llaman) es auténticamente ella misma. Por eso, tal pedagogía no será sólo operatio ad extra, sino también ad intra, porque esta floración muestra la continuidad de la comunidad eclesial, la hace

30 Proposición 16 del Congreso vocacional europeo.

${ }^{31}$ NVNE, 19a.

32 Ibid., 19b.

${ }^{33}$ Ibid., 19c. 
más rica y más viva, más dinámica y responsable del don recibido, más atenta y más conforme al mundo que cambia ${ }^{34}$.

El indicador pastoral de este estilo pedagógico será exactamente esta florescencia, o sea, el hecho de que todo el mundo (idealmente) pueda descubrir y realizar la propia vocación, o que en la comunidad creyente puedan crecer todos, ya que "en la Iglesia del Señor o se crece juntos o no crece ninguno"35.

Y si alguno piensa que todo esto desemboca en algo genérico o en un ocultamiento vocacional o no responde a las necesidades reales de la comunidad creyente reunida en torno a la eucaristía y a quien la celebra, respondemos que todo lo contrario, porque sólo este modo de entender la vocación y de interpretar la animación vocacional creará a la larga una auténtica cultura vocacional, como tierra fecunda para el nacimiento de vocaciones sacerdotales; además, este tipo de animación vocacional se dirige a todos, no sólo a algunos (a los mejores) y, precisamente porque no acaba exclusivamente en la

${ }^{34}$ NVNE, 12b: "Ahora es tiempo de que aquella llamada suscite nuevos modelos de santidad, porque Europa tiene necesidad, sobre todo, de la santidad que el momento exige, original, por tanto y, en algún modo, sin precedentes. Se necesitan personas, capaces de tender puentes para unir cada vez más a las Iglesias y a los pueblos de Europa y para reconciliar los espíritus. Son precisos padres y madres abiertos a la vida y al don de la vida; esposos y esposas que testimonien y celebren la belleza del amor humano bendecido por Dios; personas capaces de diálogo y de caridad cultural para transmitir el mensaje cristiano mediante los lenguajes de nuestra sociedad; profesionales y personas sencillas capaces de imprimir al compromiso en la vida civil y a las relaciones de trabajo y amistad, la transparencia de la verdad y la fuerza de la caridad cristiana; mujeres que descubran en la fe cristiana la posibilidad de vivir plenamente su condición femenina; sacerdotes de corazón grande, como el del Buen Pastor; diáconos permanentes que anuncian la Palabra y la libertad del servicio para con los más pobres; apóstoles consagrados, capaces de sumergirse en el mundo y en la historia con corazón contemplativo, y místicos tan familiarizados con el misterio de Dios como para saber celebrar la experiencia de lo divino y hacer ver a Dios presente en la vorágine de la acción. Europa necesita nuevos confesores de la fe y del gozo de creer, testigos que sean creyentes creíbles, valientes hasta la sangre, vírgenes que no sean tales sólo para sí mismas, sino que sepan decir a todos que la virginidad reside en el corazón de cada uno y reenvía inmediatamente al Eterno, manantial de todo amor. Nuestra tierra está ávida no sólo de personas santas, sino d comunidades santas, de tal forma enamoradas de la Iglesia y del mundo que sepan presentar al mundo mismo una Iglesia libre, abierta, dinámica, presente en la historia diaria de Europa, cercana a los sufrimientos de la gente, acogedora con todos, promotora de la justicia, solícita para con los pobres, no preocupada por su minoría numérica ni por las barreras puestas a su acción, no asustada por el clima de descristianización social (real pero quizá no tan radical ni generalizado), ni por la escasez (a menudo sólo aparente) de los resultados. ¡Será ésta la nueva santidad capaz de reevangelizar a Europa y de construir la nueva Europa!

35 Ibid., 13c. 
vocación sacerdotal, puede proponer tal ideal de vida, en alguna medida, con mayor fuerza convincente.

Es verdad que, en la práctica, no siempre es fácil evitar algunos riesgos y desequilibrios en este tipo de pastoral pedagógica vocacional, debidos sobre todo a la dificultad de dosificar inteligentemente la tensión entre la identidad eclesial ya dada y aquella por hacer. Más en concreto, el peligro que acabamos de citar de un cierto ocultamiento vocacional podrá ser real en ciertos casos, pero es precisamente por esto por lo que se revela providencial la colaboración entre las diversas fuerzas pastorales en la Iglesia, sin envidias, invasión de campos y concurrencias.

Y en todo caso, ésta es la pastoral y pedagogía vocacional de nuestro tiempo, de la que sin duda tenemos necesidad hoy.

\section{LA "CONVERSIÓN" DE LA PASTORAL VOCACIONAL: HACIA LA PASTORAL UNITARIA}

A la pastoral vocacional se le pide pues una conversión, teniendo en cuenta la realidad de un mundo en cambio: fundamentalmente que deje una pastoral vocacional concebida para un mundo que no cambia, que no ha cambiado en el tiempo y que acoja lo nuevo que el Espíritu ha creado y continúa suscitando, y adapte la propia acción a esta novedad. Más en concreto, una conversión a ser

menos autorreferencial y siempre más eclesial, abierta a la riqueza del don que viene de Dios y no ligada a una lectura cercenada e interesada de ese don,

cada vez más en diálogo con un mundo que cambia y siempre menos inflexible y cerrada en sí misma.

Sólo una pastoral convertida en esa dirección podrá colaborar con otros agentes eclesiales o con otros ámbitos pastorales.

Y si queremos todavía más en concreto definir estos dos principios, o asumir las implicaciones pedagógicas, yo no encuentro nada mejor a destacar, partiendo del así llamado decálogo indicado por el Congreso vocacional europeo, que aquel "salto de cualidad" pedido por el Papa en el Mensaje final del Congreso. Con esta expresión, señala el Documento, se quiere indicar fundamentalmente que la pastoral vocacional en Europa va unida a la necesidad de un cierto desenredo histórico y a que se dé un paso decisivo. Hay una historia...con una...prehistoria y después de las fases que se han sucedido lentamente, a lo largo de estos años, así como de los pasos naturales que se han dado, ahora deben necesariamente encaminarse hacia el estado "adulto" y maduro de la pastoral vocacional. No se trata pues de subestimar los pasos 
dados, ni de culpar a nadie por lo que no se haya hecho en el pasado; más bien nuestro sentimiento y el de toda la Iglesia es el de un sincero reconocimiento hacia aquellos hermanos y hermanas que, en condiciones nada fáciles, han ayudado con generosidad a muchos muchachos y jóvenes a buscar y encontrar su vocación. Pero se trata, en cualquier caso, de comprender una vez más la dirección que Dios, el Señor de la historia, está imprimiendo en nuestra historia, también en la rica historia de las vocaciones en Europa, hoy ante una encrucijada decisiva.

- Si, por ejemplo, la pastoral de las vocaciones nació como emergencia ante una situación de crisis y de falta de vocaciones, hoy no puede pensarse más en esta línea, motivándola desde la misma precariedad y desde una coyuntura negativa (la angustia vocacional sólo genera angustia, no vocaciones...), sino que, por el contrario, es expresión estable y coherente de la maternidad de la Iglesia, abierta al plan inescrutable de Dios, del Padre que siempre genera vida en ella;

- si en un tiempo la promoción vocacional se centraba sólo o sobre todo en algunas vocaciones, ahora se debería tender cada vez más hacia la promoción de todas las vocaciones, puesto que en la Iglesia del Señor o se crece juntos o no crece ninguno;

- si en sus inicios la pastoral vocacional solía fijarse en algunas categoría de personas ("los nuestros", los más cercanos a los ambientes de la Iglesia o aquellos que parecían mostrar de pronto un cierto interés, lo más buenos y destacados o que provenían de buenas familias, aquellos que habían hecho ya una opción creyente...), ahora se advierte cada vez más la necesidad, al menos en teoría, de extender con valentía a todos el anuncio y la oferta vocacional, en nombre del Dios que no hace distinción de personas, que acoge a pecadores en un pueblo de pecadores, que hace de Amós un profeta, sin ser hijo de profetas sino sólo recolector de sicomoros, y llama a Leví y va a casa de Zaqueo, y es capaz de hacer surgir hijos de Abrahán también de las piedras (cf. Mt 3,9);

- si antes la actividad vocacional nacía en buena parte del temor (a la extinción o al echarles de menos) y de la pretensión de mantener determinados niveles del pasado (de presencias o de obras), ahora el temor, que es siempre un tanto pagano y pésimo consejero, cede el puesto a la esperanza cristiana, que nace de la fe y se proyecta hacia la novedad y el futuro de Dios;

- si una parte de la animación vocacional es, o era, normalmente insegura y tímida, hasta el punto de parecer como si tuviera un cierto complejo de inferioridad respecto a una cultura antivocacional, hoy hace verdadera promoción vocacional sólo aquél que está animado por la certeza de que en toda persona, sin estar nadie excluido, hay un don original de Dios que espera ser descubierto; 
- si lo que se pretendía en otro tiempo parecía ser el reclutamiento y el método de propaganda, a menudo con éxitos forzados sobre la libertad del individuo o con episodios de "interferencias", ahora debe estar cada vez más claro que lo que se pretende es un servicio al individuo, a todo individuo, para que sepa discernir en su vida el proyecto de Dios para la edificación de la Iglesia, y en ello reconozca y realice su propia verdad ${ }^{36}$;

- si en épocas no muy lejanas había quien se ilusionaba con resolver la crisis vocacional haciendo opciones discutibles como, por ejemplo, "importando vocaciones" de otros lugares (a menudo sacándolas de su ambiente), hoy ninguno debería ilusionarse con resolver la crisis...evitándola, puesto que el Señor continúa llamando en cada Iglesia y en todo lugar;

- y así, en la misma línea, el "cirineo vocacional", voluntarioso y a menudo solitario improvisador, debería pasar cada vez más de una animación, hecha de iniciativas y experiencias episódicas, a una educación vocacional que se inspire en la sabiduría de un método aceptado de acompañamiento, para poder ofrecer una adecuada ayuda a quien está en actitud de búsqueda;

- en consecuencia, el mismo animador vocacional debería ser cada vez más un educador de la fe y un formador de vocaciones, y, a su vez, la animación vocacional debería ser cada vez más una acción coral $^{37}$, de toda la comunidad, religiosa o parroquial, de todo el Instituto o de toda la diócesis, de todo presbítero, consagrado o creyente, y para todas las vocaciones en toda etapa de la vida; aquí podríamos añadir, de toda expresión pastoral eclesial, especialmente de la pastoral familiar y juvenil;

- por último, digamos que ahora se pasa decididamente de la "patología del estancamiento"38, marcado por la ineficacia y la repetición, y de la resignación, que se justifica atribuyendo a la actual generación juvenil la única causa de la crisis vocacional, al coraje de interrogarse sinceramente, para captar los eventuales errores y lo que tendría que haberse hecho y no se hizo, y también para impulsar la creatividad, junto con el valor del testimonio 39 ...

Creo que estamos todos de acuerdo en un punto histórico decisivo. Estas indicaciones han contribuido a crear una mentalidad, pero no han producido todavía una nueva praxis; no representan aún el modo normal y sistemático de entender la pastoral vocacional y de operar como animadores vocacionales. ¿Qué se está haciendo, por ejemplo, en animación vocacional a gran escala, para todas las vocaciones, para todas las edades -si exceptuamos el servi-

\author{
36 Cf. Proposizioni, 20. \\ 37 Cf. Juan Pablo II, Vita consecrata, 64. \\ 38 Instrumentum laboris, 85. \\ ${ }^{39}$ Cf. NVNE, 13c.
}


cio propio de orientación en la edad juvenil-y como un compromiso que atañe a todos? Desde otro ángulo, algunos dirán que los documentos, sobre todo ciertos documentos, necesitan un cierto tiempo de incubación.

Pero quizá también habría que decir que falta una visión de conjunto del problema, con una, por consiguiente, escasa o nula colaboración entre las fuerzas activas. Una cosa es cierta: si se colabora, debe existir un cierto nivel de convergencia: en la inspiración originaria y en el objetivo a alcanzar.

\section{Punto de partida: el principio vocacional}

Ante todo es indispensable una plataforma común entre los diversos agentes que quieren interactuar juntos, un punto de partida antropológico elemental y lo más amplio posible, que pueda acoger diversas sensibilidades y perspectivas y, en las que, toda persona, idealmente, pueda reconocer el sentido de la vida. Cuanto más amplio sea el consenso que suscita, mejor para constituir el punto de partida o para encender la chispa de la colaboración. Esto debería ser así, especialmente entre los diversos ámbitos de pastoral que comparten ya el don de la fe. Pero precisamente este elemento, dado demasiado fácilmente por supuesto, tal vez ha impedido en el pasado el buscar y encontrar niveles importantes y francos de colaboración.

¿Y cuál sería este principio común en el caso de la pastoral vocacional? Sería el descubrimiento del sentido de la existencia humana encerrado en esta expresión:

la vida es un don recibido

que tiende, por su propia naturaleza,

a convertirse en un bien entregado.

Ésta es una verdad elemental sobre el hombre y la existencia terrena. Todo ser humano la puede y debe reconocer. Pero también es la base desde la que se puede partir y en torno a la cual puede desarrollarse una fecunda colaboración entre la acción educadora en la familia y entre los jóvenes, en función de la elección fundamental de vida y de todas las opciones humanas. Si quieren ser decisiones sensatas que vayan en una buena dirección, deberán respetar absolutamente este principio vocacional o esta lógica vocacional.

\section{Finalidad común: el objetivo vocacional}

Del mismo modo, será necesario, si es que queremos conseguir una colaboración, el identificar un abordaje común, el tener una misma finalidad, logrados a través de operaciones específicas y convergentes de cada uno de los agentes. Este punto de llegada implica un camino creyente y exige una opción explícita de fe; un grado de adaptación no sólo antropológica, sino 
también teológica. La finalidad común, en nuestro caso, no podrá ser otra que la de

contribuir a la edificación del cuerpo místico de Cristo que es la Iglesia, a través del crecimiento de cada miembro, cada uno llamado por Dios a realizarse según su propia vocación al servicio de todos, para que no falte a la misma Iglesia ningún don de gracia.

Más en concreto: la pastoral familiar conseguirá esta finalidad común a través de la acción de educar los padres a los hijos, porque los mismos padres viven día a día el hecho de ser cónyuges y padres y madres como una vocación verdadera y propia, generadora de vocaciones; la pastoral juvenil la conseguirá gracias a los muchos instrumentos de animación juvenil, porque el joven aprende a dejarse llamar (o a reconocer el amor de Quien lo llama) y se convence de que su plena realización y felicidad está sólo en el ofrecimiento de Dios o en el hecho de realizarse en Cristo; la pastoral vocacional la actuará con todo aquello que ayuda y estimula al creyente a percibir la voz de Dios que de mil maneras le llama, indicando caminos precisos de discernimiento y acompañando a lo largo de estos itinerarios, sin temor a proponer las llamadas que pueden parecer más radicales. Y todo esto siempre a la luz de aquella lógica que le da veracidad a la vida y que constituye un principio vocacional propio y verdadero.

Existe pues una tensión vocacional que no se puede suprimir en todas pastorales, en toda pastoral de la Iglesia, en todo ser humano, puesto que el don de la vida es como una energía que urge a la plena realización de uno, o sea, hacia la propia entrega. La pastoral vocacional tal vez tiene la función de recordarlo a todos y contribuye para que toda expresión pastoral de la Iglesia llegue a alcanzar su objetivo y tenga y exprese esta tensión vocacional, o sea, recuerda a todo agente pastoral que cualquier expresión de la pastoral cristiana merecerá tal nombre sólo si estimula en el hombre y en el creyente la actuación de esta lógica vocacional; no cesa de recordar aquello que podríamos llamar la amplitud y la profundidad del misterio de la llamada, como acción del amor de Dios, que puede llamar a las más intrépidas, impopulares y costosas opciones, y por nada comparables a una "ocupación" de otro género. Pero tiene todo el interés de que las dos pastorales "hermanas" alcancen su objetivo propio y puedan ser ellas mismas. En concreto y dicho con toda claridad, la pastoral vocacional si quiere colaborar y obtener colaboración no puede imponer a los agentes de la pastoral familiar y juvenil trabajar para el seminario, pero puede y debe estimular para que tanto la educación familiar como la juvenil sean bien comprendidas y sólidas, capaces de formar auténticos padres, dadores de vida, y jóvenes que no se avergüencen de su fe, y no exista el temor de recordar que la elección auténtica de vida se dirige siem- 
pre, por naturaleza, hacia la entrega total y radical de uno. En tal sentido, pues, y en lo que se refiere a este punto, la pastoral vocacional no tendrá miedo a proponer también la opción sacerdotal y religiosa (sin ningún peligro, como hemos podido ver, de aguar la vocación o caer en algo genérico).

He aquí por qué podemos y debemos añadir una última recomendación a aquel decálogo, que hoy aparece particularmente urgente, y es el tema de nuestro Encuentro: la recomendación de trabajar en estrecha comunión, de intentos y realizaciones prácticas, con los otros ámbitos pastorales, a partir de un principio común y a la vista de una finalidad común. De modo particular con la pastoral familiar y juvenil, con las cuales existe una convergencia natural e inevitable de objetivos y complementariedad de operaciones ${ }^{40}$. Precisamente ésta y sólo esta colaboración es la que le puede reclamar esta conversión a la pastoral vocacional, y podrá así conducirla fuera de los argumentos de la autorreferencialidad.

Es cierto que la pastoral vocacional, como ha dicho el Congreso europeo, es la perspectiva originaria y unitario-sintética de la pastoral, o la vocación es el "corazón impulsor de la pastoral unitaria"41, dado que la fe misma es la respuesta personal, libre y responsable, a la llamada de Dios; en realidad, también las otras dos pastorales reivindican centralidad, por motivos ciertamente plausibles tanto en el plano doctrinal como en el pastoral. Si la Iglesia es aquel jardín del que hablábamos antes, es indispensable que encontremos el modo de trabajar juntos sobre el mismo terreno para que pueda florecer.

\section{LA CONVERGENCIA EN ACCIÓN: ALGUNOS POSIBLES ITINERARIOS CONJUNTOS}

Daré sólo alguna indicación rápida.

\section{Pastoral familiar vocacional}

- No es un modo de hablar el afirmar que los padres son "los primeros y naturales educadores vocacionales" 42 . La primera y fundamental institución

40 Acerca de esta complementariedad, cf. A. Cencini, Complementarità della pastorale familiare nei confronti della pastorale vocazionale: Seminarium XXXV (1995) 4.

41 La pastoral vocacional es el punto de partida y el punto de llegada. En cuanto tal se presenta como "la categoría unificadora de la pastoral en general, como el destino natural de todo trabajo pastoral, el punto de llegada de las varias dimensiones, como una especie de elemento de verificación de la pastoral auténtica" (NVNE 26g).

42 NVNE, 5. 
educativa de la vocación son ellos, puesto que sólo los padres pueden transmitir la verdad de la vida, aquel sentido radical de la vida humana o aquella lógica sobre la que se construye todo el contenido vocacional, es decir, el significado de la existencia como bien recibido que tiende por naturaleza a ser bien entregado. Es aquello que en su momento llamamos principio vocacional, un verdadero y propio punto común de partida de todo itinerario educativo, verdadero en el plano antropológico y verdadero todavía más en el plano de la fe. Y lo damos por cierto, ninguno como los padres puede dar esa seguridad y, por tanto, depositar en el corazón y la mente del hijo la convicción de que la vida es efectivamente un don, más allá de cualquier vicisitud, y que como todo don tiende a permanecer como tal, y a hacerse bien que se entrega; la convicción, por tanto, también de que no sólo es necesario dar a la propia existencia esta orientación, sino que es también condición de felicidad, por lo que cualquiera puede hacer la elección de su futuro que quiera, pero si quiere ser feliz no podrá salir de esta lógica; la convicción, en fin, de que dar a la existencia una orientación hacia la entrega de sí no es una cosa extraordinaria, sino del todo natural e inevitable, precisamente porque la vida es don en sí misma. Es un aporte de enorme importancia el que la pastoral familiar da a la pastoral vocacional ${ }^{43}$. La raíz o la semilla de la disponibilidad vocacional la siembran los padres; nadie puede sustituirles en esto, y hacerlo después es siempre más difícil. Los padres que no trasmiten este sentido vocacional son unos perfectos deseducadores.

- Si queremos especificar y distinguir todavía más, dentro de un proyecto orgánico vocacional, obligación principal de la educación familiar es transmitir sobre todo la primera parte del principio vocacional: la vida es un bien recibido. Esto quiere decir que hay que conformar el sentido de la gratitud, el aprecio del don, la convicción de que todo que tengo y soy lo he recibido, que no soy el origen de mí mismo porque otro (Otro) me ha preferido a la no existencia...Desde un punto de vista psicológico, este tipo de atención constituye la así llamada seguridad emotiva, verdadera y propia conditio sine qua non para cualquier opción de vida. Sin esta seguridad no existe capacidad de decisión. Tal seguridad, en la actualidad, es más débil, y menos evidente y estable en la cultura de hoy y en la generación juvenil ${ }^{44}$.

43 "La catequesis explícitamente vocacional es catequesis sobre los valores elementales-esenciales de la vida, aquellos valores que deberían subrayarse con fuerza en la pastoral familiar que, en este punto, se convierte en el humus fecundo, y que únicamente sobre él puede nacer una disponibilidad auténticamente vocacional" (Cencini, Complementarità, 700).

44 Expresión de una cierta cultura de muerte que genera esta inseguridad es la frase de J.P. Sastre, según el cual, toda existencia "nace sin razón, se prolonga por debilidad y muere por desgracia” (cit. En Avvenire 5/II [1999] 18). 
- Esto implica que el trabajo vocacional "radical" y primario es el que hay que llevar a cabo con las familias. Si queremos vocaciones debemos cultivar las familias, formar a los novios y después a los padres para que ofrezcan este sentido de la vida humana, para que transmitan a sus hijos esta lógica vocacional de la vida, para que sean ellos mismos el primer ejemplo, en este sentido, de generosidad, gratuidad, apertura a los otros y a los necesitados en particular, de responsabilidad y solidaridad, de sobriedad y simplicidad de vida, de valentía para afrontar las dificultades y el sentido de la renuncia.

- Sobre todo es importante recordar que tal educación del sentido vocacional de la vida (educación en el amor, en última instancia) no es una cosa más que se añade a tantas tareas y deberes familiares, sino aquello que dice la verdad más íntima y profunda sobre ella. La educación vocacional no es una superestructura de la educación familiar, sino aquello que explicita su naturaleza e identidad, puesto que los padres no son llamados para dar sólo la vida física, para proporcionar la instrucción y una progresiva y variada formación general del hijo, en vista de una ocupación futura, sino que deben darle la vida eclesial, ayudarle a descubrir el puesto que tiene en la Iglesia, en la comunidad de los llamados y redimidos. Sólo quien ha llamado a la vida terrena puede educar para que se perciba la otra voz, la de Aquel que llama a la plenitud de la vida.

- Pero entonces es necesario salir de una cierta retórica que, sin embargo, está bastante enraizada en una cierta tradición cristiana, retórica que también aparece en ciertos dichos piadosos y dignos de respeto, como "ofrecer los propios hijos a la Iglesia", o la retórica de "el don más grande que Dios puede dar a una familia es tener un hijo sacerdote". Entendámonos, no quiero menospreciar todo esto ni ironizar sobre ello, el problema es la idea de vocación que está detrás de estas expresiones piadosas. En este mundo que cambia y para que cambie en una buena dirección es necesario insistir en el hecho de que, en cualquier caso, el padre creyente está llamado a ofrecer el propio hijo a Dios, es decir, a la Iglesia, a la comunidad civil, al compromiso social o político..., precisamente en razón del sentido vocacional enraizado en el significado elemental de la existencia humana ("la vida es un bien recibido que tiende..."), y que el don más grande que Dios puede hacer a una familia es que los hijos nacidos en ella respondan todos y cada uno al pensamiento de Dios sobre cada uno, respondan a aquel "sueño" que Dios tiene de ellos.

- Es obvio pues, y estamos en el punto estratégico de nuestra reflexión, que todo ello le está exigiendo, a la pastoral vocacional, a que se abra a la rica y amplia perspectiva de la idea de vocación, liberándose de la interpretación unívoca de las vocaciones llamadas de especial consagración. En provecho de la misma animación vocacional, de la Iglesia y de la comunidad civil.

Pero en provecho, sobre todo, de la concepción vocacional del matrimonio, vocación verdadera y propia en la Iglesia, que testimonia la relación de 
amor entre Cristo y su Iglesia. El punto débil y estratégico parace ser éste: la formación de los padres (desde el curso prematrimonial hasta la formación permanente) en la responsabilidad vocacional; y desde luego, hoy, es una de las vocaciones "nuevas", según el Congreso europeo: "aquella de padres y madres abiertos a la vida y al don de la vida, de esposos y esposas que, en su amor, testimonian y celebran la belleza del amor humano bendecido por Dios"45.

Esto no significa que la pastoral vocacional no pueda y no deba recordar a los padres la obligación de educar en la escucha del proyecto que Dios tiene sobre sus hijos, de tener el valor no sólo de no excluir sino de proponer positivamente las opciones que pueden parecer más difíciles, como la sacerdotal o religiosa.

\section{Pastoral juvenil vocacional}

En lo que se refiere a la relación con la pastoral juvenil, me parece que también aquí puede darse una relación de estímulo fecundo y recíproco que tendrá después una consecuencia indirecta positiva sobre las dos.

- Ante todo, y tomando como punto de partida y convergencia el principio vocacional, si corresponde a los padres el transmitir la verdad de la vida como bien recibido, corresponde a la pastoral juvenil proponer la fe como lo que encarna y engrandece, hace operativa y consecuente, en la propia historia, esta verdad (la vida es un bien recibido que tiende por naturaleza a convertirse en bien entregado), permitiendo al joven, cualquiera que sea, descubrir y realizar en plenitud la verdad de sí mismo y de la vida. Hoy, está viva, y en el mundo juvenil particularmente, una increíble sed de verdad: increíble y de hecho no creída porque frecuentemente es desconocida y se la inhibe, pero es real. La pastoral juvenil debe saberla reconocer, proponiendo al joven la fe como lo que le permite actualizar el sentido de la vida así concebido, experimentar a través de itinerarios concretos y personalizados la verdad de la conexión entre bien recibido y entregado y aceptar, más allá del límite inevitable o de experiencias negativas pasadas, la vida como un bien que necesariamente se abre a los otros.

- La pastoral juvenil cumple este servicio de búsqueda de la verdad (y, por tanto, vocacional) en la medida en que propone de modo coherente y lineal aquellos itinerarios pastorales de crecimiento en la fe (de catequesis y liturgia, de experiencias de diaconía y koinonía) como itinerarios en los cuales el joven puede cada vez más reencontrar su propia identidad y la verdad de la vida y así poder sentirse progresivamente solicitado para hacer opciones muy

45 NVNE $12 \mathrm{~b}$. 
concretas que van en la misma dirección. En concreto, si la educación familiar debe dar la certeza de la vida como bien recibido, la formación juvenil debe estimular a aceptar la conexión entre bien recibido y bien entregado, a ponerla en acción prácticamente con opciones coherentes, desarrollando una capacidad de decisión correspondiente, y encontrando cada vez más en ellas la propia identidad. No es suficiente, digamos, el estimular a la entrega o ilusionarse con el entusiasmo de que ciertas opciones (tal vez de grupo y episódicas) sean la prueba del camino formativo en sentido cristiano. Es necesario, más bien, transmitir la idea de que el paso del bien recibido al bien entregado no se puede soslayar, que es la cosa más lógica y natural que un joven pueda hacer, con la convicción de que por cuanto entregue y se entregue a la vida jamás igualará aquello que ha recibido.

- Sólo desde aquí se puede decir que la pastoral juvenil, de hecho, está creando una mentalidad vocacional, como una cultura juvenil vocacional. Mentalidad o cultura significa algo universal, que atañe a todos sin distinción, puesto que aquella verdad de la vida es verdadera para todos, y por tanto cada uno la debe sentir como verdadera para él, no sólo el joven extraordinario, de buena familia y con buenas cualidades. También en esto, probablemente, deberíamos dejar una cierta retórica, aquella que nos hace dirigir de hecho la propuesta vocacional sólo a algunos, a los mejores o que se distinguen por sus méritos, o también sólo a los creyentes y aquellos sólidamente arraigados en la fe. El discurso vocacional es para todos, porque todo está construido sobre la lógica de esta verdad que es para todos, que es de alguna manera una ley de la evolución, que atañe a todos; al joven se le debe explicar que puede hacer la opción que quiera en su vida, pero no puede en cualquier caso ignorar aquella ley fundamental, no puede escoger el retener para sí el don de la vida, no es libre para concebirse fuera de esa lógica, no puede detener el ímpetu natural del don que tiende a ser compartido con los otros. No puede, simplemente, porque iría contra una ley natural y construiría su propia infelicidad, o se convertiría en un monstruo. Por eso, la propuesta vocacional puede formar parte directamente de un camino propedéutico a la fe.

- Cuando la pastoral juvenil se mueve así, le da una impronta naturalmente vocacional a la formación de los jóvenes, conectando con la educación de base de los padres y respondiendo a aquella exigencia vocacional que no se puede suprimir y que radica en el corazón de todo adolescente o la lleva escondida. Es de todas todas imposible que un joven no quiera encontrarse consigo mismo y con aquello que hace que su vida sea digna de ser vivida, el modo de hacerla fecunda para sí y para los otros; es imposible pues que no sienta la necesidad de dejarse acompañar por un hermano o hermana mayor, mediación de otra voz que, en el alboroto ensordecedor de tantos ruidos en torno a él, le dé de cualquier modo garantía de verdad, para descubrir la pro- 
pia identidad, el propio futuro. Todo cambia en el mundo que cambia, pero no la exigencia vocacional en el corazón del joven. Esto es lo que debe creer absolutamente el animador vocacional, si no quiere convertirse en un desanimador vocacional.

- Y, entonces, la tensión vocacional no es, digámoslo una vez más, otra cosa, no es una preocupación más o un añadido que se une a tantas iniciativas que existen en relación a los jóvenes, sino que es lo que precisamente hace de la propuesta cristiana algo interesante y significativa, como una ayuda en un momento estratégico de la vida del joven, una respuesta pertinente a sus expectativas. Pero también la exigencia con la que se concluye toda propuesta educativa: y entonces yo, frente a este don, ¿qué debo hacer? Lo mismo que les sucedió a aquellos que escucharon a Pedro el día de Pentecostés, cuando sintieron traspasado el corazón (Hech 2, 37). Queremos decir que si la pastoral juvenil no es vocacional no es pastoral juvenil. Cualquiera que sea la iniciativa, catequesis, experiencia caritativa, encuentro de oración, homilía, celebración de los sacramentos... que no tenga un aspecto vocacional o que no ponga a la persona delante de sus responsabilidades y frente a aquella pregunta decisiva (¿qué debo hacer?) no merece el nombre de cristiana, no es una experiencia cristiana ${ }^{46}$. La pastoral juvenil debe hacerles descubrir a los jóvenes la dimensión dramática de la vida, y la vida es dramática en la medida en que uno descubre que sólo él puede hacer esa decisión en aquel momento de la vida, o se da cuenta del lugar que sólo él puede ocupar en la historia, él y sólo él. He aquí el paso decisivo: del joven alegre, que disfruta y consume experiencias, al joven responsable de su vida y de la salvación que sabe que ha recibido, hasta el punto también de hacer opciones, en ese sentido total, de consagración radical al anuncio de la salvación misma. En definitiva, digamos que la fe cristiana puede proponerse sólo como itinerario vocacional, y que este itinerario es un camino que debe permanecer abierto, en cualquier caso y en todo paso, a las provocaciones que vengan de Dios, hasta las más inéditas para la persona.

La pastoral vocacional aparece también, frente a estas consideraciones, como aquello que activa y mantiene estas conexiones, o es la buena memoria que impide el que olvidemos, al menos por un instante, estos empalmes y la finalidad fundamental del crecimiento cristiano: el cumplimiento del plan de Dios en cada criatura. Más en concreto y volviendo a la lógica del principio vocacional, diremos que la pastoral vocacional exige la elección de vida, por tanto la definitiva, siempre dentro de la lógica vocacional, es decir, del principio fundamental de la vida como bien recibido que tiende por naturaleza a convertirse en bien entregado. Y se cierra el círculo.

46 Cf. NVNE, 26g. 
Éstas son sólo algunas exigencias más inmediatas, pero que los agentes vocacionales podrán enriquecer mucho más, gracias a su experiencia y al conocimiento de los contextos existenciales, en el plano civil y eclesial.

Lo importante es que en todo caso se abra esta fase nueva, en la que la pastoral juvenil, la vocacional y la familiar caminen juntas hacia la "vocacionalización" de toda pastoral. 